\title{
Repairability of CAD/CAM high-density PMMA- and composite-based polymers
}

\author{
Wiegand, Annette ; Stucki, Lukas ; Hoffmann, Robin ; Attin, Thomas ; Stawarczyk, Bogna
}

\begin{abstract}
OBJECTIVE The study aimed to analyse the shear bond strength of computer-aided design and computer-aided manufacturing (CAD/CAM) polymethyl methacrylate (PMMA)- and compositebased polymer materials repaired with a conventional methacrylate-based composite after different surface pretreatments. METHODS Each 48 specimens was prepared from six different CAD/CAM polymer materials (Ambarino high-class, artBloc Temp, CAD-Temp, Lava Ultimate, Telio CAD, Everest C-Temp) and a conventional dimethacrylate-based composite (Filtek Supreme XTE, control) and aged by thermal cycling $\left(5000\right.$ cycles, $\left.5-55^{\circ} \mathrm{C}\right)$. The surfaces were left untreated or were pretreated by mechanical roughening, aluminium oxide air abrasion or silica coating/silanization (each subgroup $\mathrm{n}=12$ ). The surfaces were further conditioned with an etchrinse adhesive (OptiBond FL) before the repair composite (Filtek Supreme XTE) was adhered to the surface. After further thermal cycling, shear bond strength was tested, and failure modes were assessed. Shear bond strength was statistically analysed by twoand one-way ANOVAs and Weibull statistics, failure mode by chi(2) test (p 0.05). RESULTS Shear bond strength was highest for silica coating/silanization $>$ aluminium oxide air abrasion $=$ mechanical roughening $>$ no surface pretreatment. Independently of the repair pretreatment, highest bond strength values were observed in the control group and for the composite-based Everest C-Temp and Ambarino high-class, while PMMA-based materials (artBloc Temp, CAD-Temp and Telio CAD) presented significantly lowest values. For all materials, repair without any surface pretreatment resulted in adhesive failures only, which mostly were reduced when surface pretreatment was performed. CONCLUSIONS Repair of CAD/CAM high-density polymers requires surface pretreatment prior to adhesive and composite application. However, four out of six of the tested CAD/CAM materials did not achieve the repair bond strength of a conventional dimethacrylate-based composite. CLINICAL RELEVANCE Repair of PMMA- and composite-based polymers can be achieved by surface pretreatment followed by application of an adhesive and a conventional methacrylate-based composite.
\end{abstract}

DOI: https://doi.org/10.1007/s00784-015-1411-x

Posted at the Zurich Open Repository and Archive, University of Zurich

ZORA URL: https://doi.org/10.5167/uzh-113504

Journal Article

Accepted Version

Originally published at:

Wiegand, Annette; Stucki, Lukas; Hoffmann, Robin; Attin, Thomas; Stawarczyk, Bogna (2015). Repairability of CAD/CAM high-density PMMA- and composite-based polymers. Clinical Oral Investigations, 19(8):2007-2013.

DOI: https://doi.org/10.1007/s00784-015-1411-x 


\section{Repairability of CAD/CAM high-density PMMA- and composite-based polymers}

Annette Wiegand ${ }^{1}$, Lukas Stucki ${ }^{2}$, Robin Hoffmann ${ }^{1}$, Thomas Attin ${ }^{2}$, Bogna Stawarczyk ${ }^{3}$

${ }^{1}$ Department of Preventive Dentistry, Periodontology and Cariology, University of Göttingen,

Germany

${ }^{2}$ Clinic for Preventive Dentistry, Periodontology and Cariology, University of Zurich,

Switzerland

${ }^{3}$ Department of Prosthodontics, Ludwig-Maximilians University, Munich, Germany

\section{Short title}

Repairability of CAD/CAM-polymers

\section{Corresponding author}

Prof. Dr. Annette Wiegand

Department of Preventive Dentistry, Periodontology and Cariology

Robert-Koch-Str. 40 D-37075 Göttingen (Germany)

E-Mail annette.wiegand@med.uni-goettingen.de

Phone: +49 5513922884

Fax: +49 5513922037 


\section{Abstract}

Objective: The study aimed to analyse the shear bond strength of CAD/CAM PMMA- and composite-based polymer materials repaired with a conventional methacrylate-based composite after different surface pretreatments.

Methods: Each 48 specimens were prepared from six different CAD/CAM polymer materials (Ambarino high-class, artBloc-Temp, CAD-Temp, Lava Ultimate, Telio CAD, Everest CTemp) and a conventional dimethacrylate-based composite (Filtek supreme XTL, control) and aged by thermal cycling $\left(5000\right.$ cycles, $\left.5-55^{\circ} \mathrm{C}\right)$. The surfaces were left untreated or were pretreated by mechanical roughening, aluminium oxide air-abrasion or silica coating/silanization (each subgroup $n=12$ ). The surfaces were further conditioned with an etch\&rinse adhesive (Optibond FL) before the repair composite (Filtek supreme XTL) was adhered to the surface. After further thermal cycling, shear bond strength was tested and failure modes were assessed. Shear bond strength was statistically analysed by two- and one-way ANOVA and Weibull statistics, failure mode by Chi $^{2}$-test $(p \leq 0.05)$.

Results: Shear bond strength was highest for silica coating/silanization> aluminium oxide airabrasion=mechanical roughening $>$ no surface pretreatment. Independently of the repair pretreatment, highest bond strength values were observed in the control group and for the composite-based Everest C-Temp and Ambarino high-class, while PMMA-based materials (artBloc-temp, CAD-Temp and Telio-CAD) presented significantly lowest values. For all materials, repair without any surface pretreatment resulted in adhesive failures only, which mostly were reduced when surface pretreatment was performed.

Conclusions: Repair of CAD/CAM high-density polymers requires surface pretreatment prior to adhesive and composite application. However, four out of six of the tested CAD/CAM materials did not achieve the repair bond strength of a conventional dimethacrylate-based composite.

Clinical Relevance: Repair of PMMA- and composite-based polymers can be achieved by surface pretreatment followed by application of an adhesive and a conventional methacrylate-based composite. 


\section{Key words}

CAD/CAM polymer, repair, adhesive, PMMA, composite, shear bond strength, failure

\section{Introduction}

A range of polymer-based, pre-fabricated CAD/CAM-materials is currently available on the market for the construction of temporary and even permanent dental restorations. Prefabricated polymeric blanks are industrially polymerized under standardized conditions at high temperature and pressure to improve material properties compared to conventional polymerisation. Recent studies showed that the load-bearing capacity of 3-unit fixed partial prostheses (FDP) milled of polymethyl methacrylate (PMMA)-based CAD/CAM-blocks was significantly higher compared to manually processed ones and glass-ceramic FDPs [1-3]. Compared to conventionally-polymerized temporary materials, high-density polymers offer a wider range of translucency [4] and a higher stability against discoloration [5]. However, PMMA-based polymer materials indicated for temporary restorations present higher wear than resin-based polymeric composites indicated for permanent CAD/CAM restorations [6].

So far, CAD/CAM polymer restorations were successfully used for the pretreatment of complex cases, e.g. as diagnostic tool to reconstruct and stabilize an adequate vertical dimension of occlusion $[7,8]$. Schweiger et al. [9] suggested the use of replaceable veneers made from polymer materials on modified implant abutments to allow for an easy and quick replacement in case of chipping.

However, a clinical trial comparing CAD/CAM-manufactured composite resin crowns with ceramic crowns after 3 years of clinical service found significantly lower survival rates for the composite resin crowns [10].

Thus, longevity of polymer-based restorations - even of temporary ones - might also be affected by technical complications, such as chipping, wear or secondary caries, leading to clinical failures and requiring further operative treatment. However, no information on the repairability of polymer-based materials and the preferred intraoral repair method is available so far. Therefore, the aim of the present study was to evaluate the repairability of CAD/CAM 
polymer materials after different surface pretreatments and to compare the shear bond strength of repaired polymer materials with a conventional dimethacrylate based composite. For surface pretreatment the most frequently used methods to condition the substrate in order to create mechanical retention (roughening, air-abrasion with aluminium oxide and silica coating) were used, which showed best performance in in vitro studies so far [11]. To address also the aspect of chemical bonding, the use of an adhesive (alone or in combination with the mechanical pretreatment) was also investigated.

The null hypotheses tested were 1) the repair bond strength of polymer-based materials is not different from a conventional dimethacrylate-based composite and 2) the type of surface pretreatment does not affect shear bond strength.

\section{Material and methods}

Specimens preparation

Six types of CAD/CAM polymer materials and a conventional dimethacrylate-based composite were used in this study. The brands, batch numbers, manufacturers and chemical compositions of the materials are listed in Table 1.

The polymeric blocks were cut under water-cooling with a low-speed cutting wheel (Struers MOD 10, Struers, Ballerup, Denmark) into specimens of $15 \mathrm{~mm}$ edge length and $3.5 \mathrm{~mm}$ thickness (each material $n=48$ specimens). The specimen surfaces were polished with water-cooled silicon carbide paper (P1000-P4000, Struers, Ballerup, Denmark).

Specimens of the control group ( $\mathrm{n}=48$, Filtek Supreme XTE, 3M ESPE, USA) were fabricated incrementally using a silicone mould (15 mm x $15 \mathrm{~mm} \times 3.5 \mathrm{~mm})$. Each increment was light-cured for $20 \mathrm{~s}$ (Bluephase, Ivoclar Vivadent, Liechtenstein). Light intensity was assured to be higher than $1000 \mathrm{~mW} / \mathrm{cm}^{2}$ (Bluephase meter, Ivoclaar Vivadent, Liechtenstein). The specimens were removed from the moulds and polished with silicone carbide papers (P1000-P4000).

All specimens were aged by thermal cycling prior to repair (Willytec, Munich, Germany; 5000 cycles, 5 to $55^{\circ} \mathrm{C}$, dwell time: $20 \mathrm{~s}$, transfer time: $10 \mathrm{~s}$ ). 
Thermocycled specimens were randomly assigned to one of the subgroups (each $n=12$ ):

(a) no treatment

(b) Mechanical roughening simulating diamond bur abrasion. Surfaces were ground with a diamond disk (40 $\mu \mathrm{m}$, Intensiv, Montagnola, Switzerland) at $1.3 \mathrm{~N}$ for $8 \mathrm{~s}$.

(c) Air-abrasion with aluminium oxide $(50 \mu \mathrm{m}$, Renfert, Hilzingen, Germany) for $10 \mathrm{~s}$ at a distance of $10 \mathrm{~mm}\left(90^{\circ}\right)$ and 2.8 bar air pressure. Remnants of air-abrasion were air blown.

(d) Silica coating/silanization. Surfaces were silica coated (30 $\mu \mathrm{m}$, CoJet, 3M ESPE, Seefeld, Germany) for 10 a at a distance of $10 \mathrm{~mm}\left(90^{\circ}\right)$ and 2.8 bar air pressure. Loose particles were air blown. Silane coupling agent (Monobond Plus, Ivoclar Vivadent, Schaan, Liechtenstein was applied and allowed to evaporate for $60 \mathrm{~s}$ as recommended by the manufacturer.

Then, all surfaces were further conditioned with an etch\&rinse adhesive (Optibond FL, Kerr, Orange, USA), which was applied as recommended by the manufacturer and light cured for $20 \mathrm{~s}$.

The repair composite (Filtek Supreme XTE) was adhered onto the specimen surface using acrylic hollow cylinders (inner diameter: $2.9 \mathrm{~mm}$, height: $3.5 \mathrm{~mm}$ ). The composite was packed against the surface in a $2 \mathrm{~mm}$ thick increment and light cured for $20 \mathrm{~s}$ by applying the curing unit directly onto the acrylic cylinder.

All specimens were then submitted to an additional thermal cycling procedure (5000 cycles, between 5 and $55^{\circ} \mathrm{C}$, dwell time: $20 \mathrm{~s}$, transfer time: $10 \mathrm{~s}$ ). The set-up is illustrated in figure 1.

Shear bond strengths and failure analysis

Bond strength was tested with an universal testing machine (Z010, Zwick, Ulm, Germany). A shear force was applied to the adhesive interface through a chisel-shaped loading device at a crosshead speed of $1 \mathrm{~mm} / \mathrm{min}$. Load at debonding was recorded and shear bond strength $\sigma$ was calculated using the load at failure $F(N)$ and the adhesive area $A\left(\mathrm{~mm}^{2}\right): \sigma=F / A$. 
The debonded area was examined for failure mode analysis with a stereomicroscope at $25 \mathrm{x}$ magnification (M3Z, Leica Microsystems, Wetzlar, Germany). Failure mode was considered as adhesive if it occurred at the interface, as cohesive if the failure affected at least parts of the polymer substrate or the repair composite or as mixed.

\section{Statistical analysis}

Shear bond strength (MPa) data were submitted to Kolmogorov-Smirnov and Shapiro-Wilk tests to check normal distribution of the data. Normal distribution was found in $89 \%$ of the subgroups (25 out of 28 ), thus, for all statistical tests a normal distribution assumption was employed. Two-and one-way ANOVAs followed by Scheffé post-hoc tests were performed (SPSS Version 20, SPSS INC, Chicago, IL, USA). Additionally, Weibull distribution parameters (Weibull modulus $\mathrm{m}$, characteristic bond strength $\sigma_{0}$ ) were calculated using the maximum likelihood estimation method at 95\% confidence level (MINITAB Version 14, State College, PA, USA) [12].

Relative frequencies of failure types together with the corresponding 95\% confidence intervals according to the Ciba Geigy Tables were provided. A Chi ${ }^{2}$ test was used in order to analyse differences of failure types in different groups [13].

In all tests, level of significance was set at $p \leq 0.05$.

\section{Results}

Two-way ANOVA revealed the type of substrate, the repair pretreatment and the interaction between both factors to be significant with respect to shear bond strength. Generally, significantly highest bond strength values were obtained by silica coating/silanization (mean of all subgroups: $19.9 \pm 7.3 \mathrm{MPa})$, followed by aluminium oxide sandblasting $(15.8 \pm 5.5$ $\mathrm{MPa})$ and mechanical roughening $(15.3 \pm 7.6 \mathrm{MPa})$, which were not significantly different from each other. Lowest bond strength values were obtained when no surface pretreatment was performed $(4.8 \pm 4.9 \mathrm{MPa})$. 
Independently of the repair pretreatment, mean shear bond strength was highest for the control group (mean of all subgroups: $18.6 \pm 7.6 \mathrm{MPa}$ ), Ambarino high-class $(18.8 \pm 8.6$ $\mathrm{MPa}$ ) and Everest C-Temp (18.2 $\pm 7.9 \mathrm{MPa})$, while all other CAD/CAM polymers exhibited significantly lower bond strength values (LAVA Ultimate: $13.3 \pm 6.9 \mathrm{MPa}$; Telio CAD: $10.1 \pm$ 7.3; CAD Temp: $9.7 \pm 7.2 \mathrm{MPa}$, artBloc-Temp: $9.0 \pm 6.7 \mathrm{MPa}$ ).

Shear bond strength values of all subgroups are presented in Table 2. Within one substrate, mean shear bond strength and characteristic strength $\sigma_{\circ}$ were lowest when no additional pretreatment was performed, while silica coating/silanization mostly resulted in highest values.

In general, lowest Weibull moduli were obtained for all CAD/CAM polymeric groups $(\mathrm{m}=0.2$ - 1.8) and the control group $(m=3.8)$ without any pretreatment. Mechanical roughening of Everest C-Temp $(m=11.0)$ and silica coating of Ambarino high-class ( $m=9.3$ ) showed the highest Weibull moduli. The Weibull statistics are presented in Table 2.

Comparisons between the substrates within one repair pretreatment also showed highest shear bond strength values and characteristic strengths $\sigma_{0}$ for Filtek Supreme XTE, Everest C-Temp and Ambarino high-class. artBloc-temp, CAD-Temp and Telio-CAD presented significantly lowest shear bond strength values characteristic strength $\sigma_{0}$, independently of the pretreatment.

Failure types were significantly different among the groups $\left(\mathrm{Chi}^{2}\right.$-test: $\left.\mathrm{p}<0.05\right)$. For all materials, repair without any surface pretreatment resulted in adhesive failures only. Except for artBloc-Temp and Telio-CAD, any kind of surface pretreatment reduced the amount of adhesive failures (Table 3)

\section{Discussion}

This study showed that polymeric CAD/CAM materials require mechanical surface pretreatment - ideally in form of silica coating/silanization - prior to repair, and that Fibreglasreinforced polymers and nanofilled composites but not PMMA-based materials achieve repair 
bond strength values comparable to a conventional dimethacrylate-based composite used for direct restorations. Thus, both null hypotheses were rejected.

Shear bond strength values of Filtek Supreme XTE were in accordance to previous studies $[14,15]$ and used as a reference value for the CAD/CAM repair. Although it is difficult to define a clinically relevant value for bond strength after repair, most in vitro studies presented repair bond strength values of dimethacrylate-based direct composites of at least $20 \mathrm{MPa}$, depending on the kind of composite material and the repair method [15]. Mean repair bond strength of Filtek Supreme XTE amounted to 18.6 MPa and was even higher, when the repair surface was pretreated mechanically instead of conditioned with an adhesive system only, thus presenting an adequate reference for the repair of CAD/CAM polymers.

As repair restorations usually become necessary after months or years of clinical service and require long-term stability, both the substrate and the repaired specimens were extensively aged by thermocycling. Shear bond strength of repaired dimethacrylate-based direct composites is significantly decreased by aging and affected by the kind of aging condition $[16,17]$. Adhesion between PMMA-based polymer restorations and conventional resin cements has also shown to be impaired by aging [18], indicating that thermocycling might further reduce the residual monomer content by reducing the number of carbon-carbon double bonds. Moreover, thermocycling might lead to mechanical stress on the bonding area of the repaired substrate. However, it is also discussed that thermocycling might increase the repair bond strength by intensifying the process of post-polymerisation between polymeric CAD/CAM materials and adhesive resins [19].

Adhesion was tested only on the pure polymer substrate, not taking into account that under clinical conditions the defective restoration is often surrounded by dental hard tissue, which also needs to be conditioned prior to application of the repair material. Mixed surfaces might be more difficult to repair [20], and need to be investigated in further studies.

Generally, this study showed that adhesive conditioning alone without micromechanical retention is not adequate to obtain sufficient repair bond strength, especially when PMMAbased materials are considered. As industrially polymerized materials present a high degree 
of conversion, it can be assumed that the amount of residual monomer or free radicals is very low or even insufficient to allow for co-polymerisation. Moreover, monomers of the adhesive system (Bis-GMA, HEMA; GDMA) and of the composite (Bis-GMA, UDMA, TEGDMA, bis-EMA(6)) might not co-polymerise with PMMA-based materials [18].

Mechanical pretreatment prior to adhesive application increased repair bond strength of all materials. Based on the above mentioned, it is likely that the repair bond strength of PMMAbased materials is mainly depending on micromechanical retention rather than on a chemical interaction between PMMA and the adhesive. Stawarczyk et al. [21] showed that the bond strength between air-abraded PMMA-based polymer and a hybrid composite was not further increased by adhesive conditioning. In contrast, another study demonstrated that without further conditioning no adhesion between air-abraded CAD/CAM polymers and resin composite cements could be achieved $[19,21]$.

In contrast to the PMMA-based materials, the fibreglas-reinforced polymer and the polymers based on Bis-GMA and/or UDMA resulted in repair bond strength values similar to the control. In these cases, the adhesive might penetrate into the surface irregularities improving mechanical retention and at the same time bond to silane-coated filler particles of the polymer. Compared to the PMMA-based polymers the filler content of Lava Ultimate and Ambarino high-class is significantly higher, thus explaining higher bond strength values. Silane application after silica coating might further increase bond strength as it enhances wettability of the substrate and establish bonding between unreacted monomers and inorganic fillers or silica coated surfaces, respectively [22].

Lava Ultimate (UDMA-based polymer) showed slightly lower repair bond strength values compared to Ambarino high-class (Bis-GMA, UDMA) and Everest C-Temp (fibreglasreinforced polymer). Provided that dimethacrylate resins are polymerized under the same experimental conditions, UDMA showed a higher degree of conversion and a polymerization rate than Bis-GMA, indicating that further co-polymerisation might be more difficult for UDMA [23]. 
Within the limitations of this in vitro study it is concluded that CAD/CAM polymers can be repaired after adequate mechanical surface pretreatment, ideally silica coating/silanization. However, repair bond strength values of PMMA-based materials are significantly lower than of methacrylate-based direct composites.

\section{Conflict of interest}

The authors declare that they have no financial or other relationships that might lead to actual or potential conflict of interest. The major parts of this study were self-funded by the authors and their institutions. The polymer and compsite materials used were provided by the manufacturers. 


\section{References}

1. Stawarczyk B, Ender A, Trottmann A, Özcan M, Fischer J, Hämmerle CHF (2012) Load-bearing capacity of CAD/CAM milled polymeric three-unit fixed dental prostheses: Effect of aging regimens. Clin Oral Invest 16:1669-1677

2. Alt V, Hannig M, Wöstmann B, Balkenhol M (2011) Fracture strength of temporary fixed partial dentures: CAD/CAM versus directly fabricated restorations. Dent Mater 27:339347

3. Göncü Basaran E, Ayna E, Vallitu PK, Lassila LV (2011) Load-bearing capacity of handmade and computer-aided design--computer-aided manufacturing-fabricated three-unit fixed dental prostheses of particulate filler composite 69:144-150

4. Güth JF, Zuch T, Zwinge S, Engels J, Stimmelmayr M, Edelhoff D (2013) Optical properties of manually and CAD/CAM-fabricated polymers. Dent Mater J 32:865-871

5. Stawarczyk B, Sener B, Trottmann A, Roos M, Ozcan M, Hämmerle CHF (2012) Discoloration of manually fabricated resins and industrially fabricated CAD/CAM blocks versus glass-ceramic: Effect of storage media, duration, and subsequent polishing. Dent Mater J 31:377-383

6. Mörmann WH, Stawarczyk B, Ender A, Sener B, Attin T, Mehl A (2013) Wear characteristics of current aesthetic dental restorative CAD/CAM materials: Two-body wear, gloss retention, roughness and Martens hardness. J Mech Behav Biomed Mater 20:113-125

7. Edelhoff D, Beuer F, Schweiger J, Brix O, Stimmelmayr M, Güth JF (2012) CAD/CAMgenerated high-density polymer restorations for the pretreatment of complex cases: $A$ case report. Quintessence Int 43:457-467

8. Güth JF, Almeida e Silva JS, Ramberger M, Beuer F, Edelhoff D (2012) Treatment concept with CAD/CAM-fabricated high-density polymer temporary restorations. J Esthet Restor Dent 24:310-320

9. Schweiger J, Neumeier P, Stimmelmayr M, Beuer F, Edelhoff D (2013) Macro-retentive replaceable veneers on crowns and fixed dental prostheses: A new approach in implant-prosthodontics. Quintessence Int 44:341-349 
10. Vanoorbeek S, Vandamme K, Lijnen I, Naert I (2010) Computer-aided design/computer-assisted manufactured composite resin versus ceramic single-tooth restorations: A 3-year clinical study. Int J Prosthodont 23:223-230

11. Hickel R, Brüshaver K, llie N (2013) Repair of restorations - criteria for decision making and clinical recommendations. Dent Mater 29:28-50

12. Roos M, Stawarczyk B (2012) Evaluation of bond strength of resin cements using different general-purpose statistical software packages for two-parameter Weibull statistics. Dent Mater 28:e76-e88

13. Geigy Scientific Tables. 8th. 1980. Basel, Switzerland, CIBA-GEIGY.

14. Rinastiti M, Özcan M, Siswomihardjo W, Busscher HJ (2011) Effects of surface conditioning on repair bond strengths of non-aged and aged microhybrid, nanohybrid, and nanofilled composite resins. Clin Oral Invest 15:625-633

15. Baur V, Ilie N (2013) Repair of dental resin-based composite. Clin Oral Invest 17:601608

16. Brendeke J, Ozcan M (2007) Effect of physicochemical aging conditions on the composite-composite repair bond strength. J Adhes Dent 9:399-406

17. Ozcan M, Cura C, Brendeke J (2010) Effect of aging conditions on the repair bond strength of a microhybrid and a nanohybrid resin composite. J Adhes Dent 12:451-459

18. Stawarczyk B, Basler T, Ender A, Roos M, Özcan M, Hämmerle CHF (2012) Effect of surface conditioning with airborne-particle abrasion on the tensile strength of polymeric CAD/CAM crowns luted with self-adhesive and conventional resin cements. J Prosthet Dent 107:94-101

19. Bähr N, Keul C, Edelhoff D, Eichberger M, Roos M, Gernet W, Stawarczyk B (2013) Effect of different adhesives combined with two resin composite cements on shear bond strength to polymeric CAD/CAM materials. Dent Mater J 32:492-501

20. Özcan M, Pekkan G (2013) Effect of different adhesion strategies on bond strength of resin composite to composite-dentin complex. Oper Dent 38:63-72

21. Stawarczyk B, Trottmann A, Hämmerle CHF, Özcan M (2013) Adhesion of veneering resins to polymethylmethacrylate-based CAD/CAM polymers after various surface conditioning methods. Acta Odontol Scand 71:1142-1148 
22. Ozcan M, Barbosa SN, Melo RM, Galhano AP, Bottino MA (2007) Effect of surface conditioning methods on the microtensile bond strength of resin composite to composite after aging conditions. Dent Mater 2007:1276-1282

23. Gajewski VE, Pfeifer CS, Froes-Salgado NR, Boaro LC, Braga RR (2012) Monomers used in resin composites: degree of conversion, mechanical properties and water sorption/solubility. Braz Dent J 23:508-514 
Figure 1 Set-up of specimen preparation

Cutting $(A)$ and polishing $(B)$ of polymeric blocks followed by thermocycling $(C)$. Specimens were pretreated by mechanical roughening, aluminium oxide air-abrasion or silica coating/silanization (D) or left untreated before the adhesive (E) was applied and light-cured. An acrylic cylinder was fixed on the specimens surface $(F)$ and filled with the repair composite $(G)$ followed by additional thermocycling $(H)$ and shear bond strength testing (I).

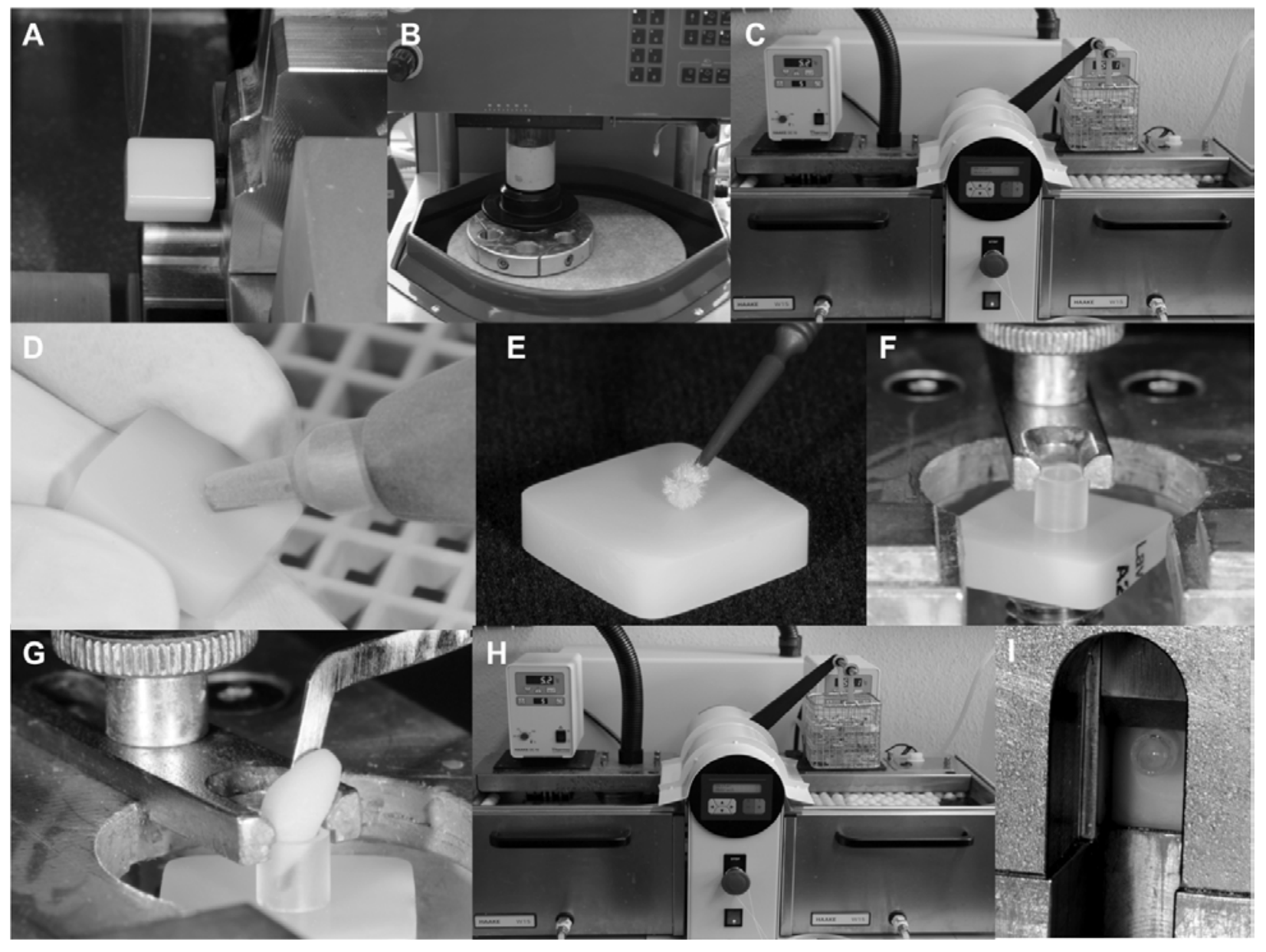


Table 1: Materials, manufacturers, composition and indication of the different materials used in this study.

\begin{tabular}{|c|c|c|c|c|}
\hline Material & Manufacturer & Lot-No & Composition & Indication \\
\hline $\begin{array}{l}\text { Ambarino high- } \\
\text { class }\end{array}$ & $\begin{array}{l}\text { Creamed, Marburg, } \\
\text { Germany }\end{array}$ & 090313 & $\begin{array}{l}\text { Highly crosslinked Bis-GMA, UDMA, } \\
\text { Butandiaol dimethacrylate, } 70.1 \mathrm{wt} \% \\
\text { anorganic silica nanofillers }\end{array}$ & $\begin{array}{l}\text { Definitive inlay, onlay, veneer, partial crown and } \\
\text { crown restorations, FDP (max. } 3 \text { unit), } \\
\text { telescopic prostheses, tertiary structures }\end{array}$ \\
\hline artBloc-Temp & $\begin{array}{l}\text { Merz Dental, } \\
\text { Lütjenburg, } \\
\text { Germany }\end{array}$ & 22813 & $\begin{array}{l}\text { Highly-crosslinked PMMA (OMP: } \\
\text { organically modified polymer network), } \\
\text { no fillers }\end{array}$ & $\begin{array}{l}\text { Long-term temporization of crowns, partial } \\
\text { crowns, bridges ( } 3 \text { units }) \text { and implant } \\
\text { restoration }\end{array}$ \\
\hline CAD-Temp & $\begin{array}{l}\text { VITA Zahnfabrik, } \\
\text { Bad Säckingen, } \\
\text { Germany }\end{array}$ & - & $\begin{array}{l}\text { 83-86 wt\% PMMA, } 14 \text { wt\% micro-filler } \\
\text { (silica), pigments }(<0.1 \%)\end{array}$ & $\begin{array}{l}\text { Multi-unit, fully or partially anatomical long-term } \\
\text { temporary bridges with up to } 2 \text { pontics }\end{array}$ \\
\hline Telio CAD & $\begin{array}{l}\text { Ivoclar Vivadent, } \\
\text { Schaan, } \\
\text { Liechtenstein }\end{array}$ & S20793 & $\begin{array}{l}99.5 \text { wt } \% \text { PMMA, no fillers, pigment }(<1 \\
\text { wt\%) }\end{array}$ & $\begin{array}{l}\text { Temporary crowns and bridges and implant- } \\
\text { supported restorations }\end{array}$ \\
\hline Everest C-Temp & $\begin{array}{l}\text { KaVo, Biberach, } \\
\text { Germany }\end{array}$ & 5310 & Fibreglas-reinforced polymer & $\begin{array}{l}\text { Long-term temporary restorations, } \\
\text { frameworks for up to } 6 \text { units }\end{array}$ \\
\hline Lava Ultimate & $\begin{array}{l}\text { 3M ESPE, } \\
\text { Rüschlikon, } \\
\text { Switzerland }\end{array}$ & N490809 & $\begin{array}{l}\text { UDMA, Resin Nano Ceramic containing } \\
\text { approximately } 79 \text { wt } \% \text { nanoceramic } \\
\text { particles }\end{array}$ & $\begin{array}{l}\text { Permanent, single-unit restorations (crowns, } \\
\text { implant-crowns, onlay, inlay, veneer) }\end{array}$ \\
\hline $\begin{array}{l}\text { Filtek } \quad \text { Supreme } \\
\text { XTE } \\
\text { (control) }\end{array}$ & $\begin{array}{l}\text { 3M ESPE, } \\
\text { Rüschlikon, } \\
\text { Switzerland }\end{array}$ & N344843 & $\begin{array}{l}\text { Bis-GMA, UDMA, TEGDMA, bis-EMA(6), } \\
\text { silica fillers, zircona fillers }\end{array}$ & $\begin{array}{l}\text { Direct anterior and posterior restorations } \\
\text { (including occlusal surfaces), Core build-ups, } \\
\text { Splinting, Indirect restorations (including inlays, } \\
\text { onlays and veneers) }\end{array}$ \\
\hline
\end{tabular}


Table 2: Shear bond strength (mean \pm standard deviation) and Weibull parameters (95\% confidence intervalls) in the different groups.

\begin{tabular}{|c|c|c|c|c|c|}
\hline Material & $\begin{array}{l}\text { Repair } \\
\text { pretreatment }\end{array}$ & Mean \pm SD & $95 \% \mathrm{Cl}$ & $\begin{array}{l}\text { Weibull Modus } \\
(95 \% \mathrm{Cl})\end{array}$ & $\begin{array}{l}\text { Characteristic } \\
\text { strength }(95 \% \mathrm{Cl})\end{array}$ \\
\hline \multirow[t]{4}{*}{ Ambarino } & none & $7.6 \pm 4.9^{\mathrm{a} / \mathrm{BC}}$ & $4.3 ; 10.7$ & $1.5(0.8 ; 2.5)^{a / b}$ & $8.3(5.5 ; 12.3)^{a / B C}$ \\
\hline & roughening & $20.8 \pm 4.6^{\mathrm{b} / \mathrm{BC}}$ & $17.7 ; 23.8$ & $5.5(3.4 ; 8.7)^{\mathrm{b} / \mathrm{BC}}$ & $22.6(20.1 ; 25.2)^{\mathrm{b} / \mathrm{BC}}$ \\
\hline & $\mathrm{Al}_{2} \mathrm{CO}_{3}$ air-abrasion & $20.0 \pm 6.3^{\mathrm{b} / \mathrm{B}}$ & $15.9 ; 24.1$ & $3.8(2.2 ; 6.0)^{\mathrm{ab} / \mathrm{A}}$ & $22.2(18.8 ; 26.1)^{\mathrm{b} / \mathrm{B}}$ \\
\hline & $\mathrm{SiO}_{2}$ coating & $26.9 \pm 3.5^{\mathrm{C} / \mathrm{B}}$ & $24.5 ; 29.2$ & $9.3(5.8 ; 14.5)^{\mathrm{b} / \mathrm{B}}$ & $28.4(26.4 ; 30.3)^{\mathrm{C} / \mathrm{C}}$ \\
\hline \multirow{4}{*}{$\begin{array}{l}\text { artBloc- } \\
\text { Temp }\end{array}$} & none & $0.0 \pm 0.0^{a / A}$ & $0.0 ; 0.0$ & - & - \\
\hline & roughening & $9.0 \pm 3.3^{\mathrm{b} / \mathrm{C}}$ & $6.8 ; 11.1$ & $3.3(2.0 ; 5.3)^{a / B}$ & $10.0(8.2 ; 12.1)^{\mathrm{a} / \mathrm{A}}$ \\
\hline & $\mathrm{Al}_{2} \mathrm{CO}_{3}$ air-abrasion & $11.7 \pm 4.4^{\mathrm{DC} / \mathrm{A}}$ & $8.8 ; 14.5$ & $3.0(1.8 ; 4.5)^{a / A}$ & $13.1(10.5 ; 16.1)^{\mathrm{ab} / \mathrm{A}}$ \\
\hline & $\mathrm{SiO}_{2}$ coating & $15.3 \pm 4.4^{\mathrm{C} / \mathrm{A}}$ & $12.4 ; 18.2$ & $4.2(2.5 ; 6.6)^{a / A B}$ & $16.9(14.5 ; 19.5)^{\mathrm{b} / \mathrm{A}}$ \\
\hline \multirow[t]{4}{*}{ CAD-Temp } & none & $2.2 \pm 3.6^{\mathrm{a} / \mathrm{A}}$ & $-0.1 ; 4.5$ & $0.2(0.1 ; 0.4)^{a / A}$ & $0.2(0.0 ; 2.0)^{a / A}$ \\
\hline & roughening & $8.1 \pm 4.0^{\mathrm{ab} / \mathrm{c}}$ & $5.5 ; 10.6$ & $2.2(1.2 ; 3.7)^{\mathrm{b} / \mathrm{AB}}$ & $9.1(6.9 ; 11.9)^{\mathrm{b} / \mathrm{A}}$ \\
\hline & $\mathrm{Al}_{2} \mathrm{CO}_{3}$ air-abrasion & $13.0 \pm 3.7^{D C / A B}$ & $10.6 ; 15.4$ & $3.5(2.3 ; 5.2)^{b / A}$ & $14.4(12.0 ; 17.1)^{\mathrm{bC} / \mathrm{A}}$ \\
\hline & $\mathrm{SiO}_{2}$ coating & $15.7 \pm 8.2^{\mathrm{C} / \mathrm{A}}$ & $10.4 ; 20.9$ & $2.1(1.2 ; 3.3)^{b / A}$ & $17.6(13.0 ; 23.5)^{C / A B}$ \\
\hline \multirow[t]{4}{*}{ Telio CAD } & none & $1.1 \pm 2.6^{\mathrm{a} / \mathrm{A}}$ & $-0.6 ; 2.8$ & $0.2(0.1 ; 0.4)^{a / A}$ & $0.1(0.0 ; 0.4)^{a / A}$ \\
\hline & roughening & $8.4 \pm 4.6^{b / C}$ & $5.4 ; 11.3$ & $1.1(0.5 ; 1.8)^{b / A}$ & $8.4(4.7 ; 14.6)^{b / A}$ \\
\hline & $\mathrm{Al}_{2} \mathrm{CO}_{3}$ air-abrasion & $15.8 \pm 4.7^{\mathrm{C} / \mathrm{AB}}$ & $12.8 ; 18.8$ & $4.0(2.4 ; 6.2)^{\mathrm{C} / \mathrm{A}}$ & $17.5(15.0 ; 20.4)^{\mathrm{C} / \mathrm{AB}}$ \\
\hline & $\mathrm{SiO}_{2}$ coating & $15.0 \pm 5.2^{\mathrm{C} / \mathrm{A}}$ & $11.7 ; 18.3$ & $3.4(2.0 ; 5.3)^{\mathrm{C} / \mathrm{A}}$ & $16.7(14.0 ; 20.0)^{\mathrm{bc} / \mathrm{A}}$ \\
\hline \multirow{4}{*}{$\begin{array}{l}\text { Everest } \\
\text { C-Temp }\end{array}$} & none & $9.4 \pm 5.3^{a / c}$ & $6.0 ; 12.8$ & $1.8(1.0 ; 2.9)^{a / b}$ & $10.5(7.4 ; 14.6)^{\mathrm{a} / \mathrm{C}}$ \\
\hline & roughening & $21.1 \pm 2.1^{\mathrm{bC} / \mathrm{BC}}$ & $19.7 ; 22.6$ & $11.0(7.0 ; 17.0)^{\mathrm{b} / \mathrm{C}}$ & $22.1(20.8 ; 23.4)^{\mathrm{b} / \mathrm{C}}$ \\
\hline & $\mathrm{Al}_{2} \mathrm{CO}_{3}$ air-abrasion & $16.2 \pm 5.6^{\mathrm{b} / \mathrm{AB}}$ & $12.6 ; 19.8$ & $3.2(2.0 ; 4.9)^{\mathrm{ab} / \mathrm{A}}$ & $18.1(14.8 ; 21.8)^{\mathrm{b} / \mathrm{AB}}$ \\
\hline & $\mathrm{SiO}_{2}$ coating & $26.0 \pm 6.3^{\mathrm{c} / \mathrm{B}}$ & $21.9 ; 30.0$ & $5.5(3.3 ; 9.0)^{b / A B}$ & $28.2(25.2 ; 31.5)^{c / C}$ \\
\hline \multirow{4}{*}{$\begin{array}{l}\text { LAVA } \\
\text { Ultimate }\end{array}$} & none & $4.2 \pm 2.4^{\mathrm{a} / \mathrm{AB}}$ & $2.6 ; 5.8$ & $1.9(1.1 ; 3.0)^{a / B}$ & $4.7(3.3 ; 6.5)^{a / B}$ \\
\hline & roughening & $15.9 \pm 5.3^{\mathrm{b} / \mathrm{B}}$ & $12.5 ; 19.3$ & $3.8(2.2 ; 6.2)^{\mathrm{ab} / \mathrm{b}}$ & $17.7(15.0 ; 20.7)^{\mathrm{bC} / \mathrm{B}}$ \\
\hline & $\mathrm{Al}_{2} \mathrm{CO}_{3}$ air-abrasion & $14.4 \pm 3.3^{\mathrm{b} / \mathrm{AB}}$ & $12.2 ; 16.5$ & $5.3(3.2 ; 8.3)^{\mathrm{b} / \mathrm{A}}$ & $15.6(13.8 ; 17.6)^{b / A}$ \\
\hline & $\mathrm{SiO}_{2}$ coating & $18.8 \pm 5.1^{\mathrm{D} / \mathrm{AB}}$ & $15.5 ; 22.1$ & $4.5(2.7 ; 7.1)^{\mathrm{ab} / \mathrm{AB}}$ & $20.7(18.0 ; 23.7)^{C / A B}$ \\
\hline \multirow{4}{*}{$\begin{array}{l}\text { Filtek } \\
\text { Supreme } \\
\text { XTE } \\
\text { (control) }\end{array}$} & none & $8.8 \pm 2.7^{a / B C}$ & $7.0 ; 10.6$ & $3.8(2.3 ; 6.1)^{a / B}$ & $9.7(8.2 ; 11.4)^{a / C}$ \\
\hline & roughening & $23.8 \pm 5.5^{\mathrm{b} / \mathrm{c}}$ & $20.2 ; 27.3$ & $4.9(3.0 ; 7.7)^{a / B C}$ & $25.9(22.8 ; 29.3)^{b / C}$ \\
\hline & $\mathrm{Al}_{2} \mathrm{CO}_{3}$ air-abrasion & $19.9 \pm 4.6^{\mathrm{b} / \mathrm{B}}$ & $16.9 ; 22.8$ & $5.1(3.1 ; 8.0)^{a / A}$ & $21.6(19.1 ; 24.4)^{\mathrm{b} / \mathrm{B}}$ \\
\hline & $\mathrm{SiO}_{2}$ coating & $21.8 \pm 6.5^{\mathrm{b} / \mathrm{AB}}$ & $7.7 ; 26.0$ & $4.6(2.6 ; 7.7)^{a / A B}$ & $23.7(20.8 ; 27.0)^{\mathrm{b} / \mathrm{BC}}$ \\
\hline
\end{tabular}

Significant differences between the different surface pretreatments within one material are marked with different small letters. Significant differences between the different materials within the same surface pretreatement are marked by different capital letters. 
Table 3: Relative frequencies of failures (95\% confidence intervals) in the different subgroups.

\begin{tabular}{|c|c|c|c|c|}
\hline Material & $\begin{array}{l}\text { Repair } \\
\text { pretreatment }\end{array}$ & Adhesive (\%) & Cohesive (\%) & Mixed (\%) \\
\hline \multirow[t]{4}{*}{ Ambarino } & none & $100(72 ; 100)$ & $0(0 ; 27)$ & $0(0 ; 27)$ \\
\hline & roughening & $50(20 ; 79)$ & $0(0 ; 27)$ & $50(20 ; 79)$ \\
\hline & $\mathrm{Al}_{2} \mathrm{CO}_{3}$ air-abrasion & $17(1 ; 49)$ & $33(8 ; 66)$ & $50(20 ; 79)$ \\
\hline & $\mathrm{SiO}_{2}$ coating & $8(0 ; 39)$ & $75(41 ; 95)$ & $17(1 ; 49)$ \\
\hline \multirow{4}{*}{$\begin{array}{l}\text { artBloc- } \\
\text { Temp }\end{array}$} & none & $100(72 ; 100)$ & $0(0 ; 27)$ & $0(0 ; 27)$ \\
\hline & roughening & $100(72 ; 100)$ & $0(0 ; 27)$ & $0(0 ; 27)$ \\
\hline & $\mathrm{Al}_{2} \mathrm{CO}_{3}$ air-abrasion & $100(72 ; 100)$ & $0(0 ; 27)$ & $0(0 ; 27)$ \\
\hline & $\mathrm{SiO}_{2}$ coating & $100(72 ; 100)$ & $0(0 ; 27)$ & $0(0 ; 27)$ \\
\hline \multirow[t]{4}{*}{ CAD-Temp } & none & $100(72 ; 100)$ & $0(0 ; 27)$ & $0(0 ; 27)$ \\
\hline & roughening & $100(72 ; 100)$ & $0(0 ; 27)$ & $0(0 ; 27)$ \\
\hline & $\mathrm{Al}_{2} \mathrm{CO}_{3}$ air-abrasion & $67(33 ; 91)$ & $0(0 ; 27)$ & $33(8 ; 66)$ \\
\hline & $\mathrm{SiO}_{2}$ coating & $83(50 ; 98)$ & $0(0 ; 27)$ & $17(1 ; 49)$ \\
\hline \multirow[t]{4}{*}{ Telio CAD } & none & $100(72 ; 100)$ & $0(0 ; 27)$ & $0(0 ; 27)$ \\
\hline & roughening & $100(72 ; 100)$ & $0(0 ; 27)$ & $0(0 ; 27)$ \\
\hline & $\mathrm{Al}_{2} \mathrm{CO}_{3}$ air-abrasion & $100(72 ; 100)$ & $0(0 ; 27)$ & $0(0 ; 27)$ \\
\hline & $\mathrm{SiO}_{2}$ coating & $100(72 ; 100)$ & $0(0 ; 27)$ & $0(0 ; 27)$ \\
\hline \multirow{4}{*}{$\begin{array}{l}\text { Everest C- } \\
\text { Temp }\end{array}$} & none & $100(72 ; 100)$ & $0(0 ; 27)$ & $0(0 ; 27)$ \\
\hline & roughening & $33(8 ; 66)$ & $0(0 ; 27)$ & $67(33 ; 91)$ \\
\hline & $\mathrm{Al}_{2} \mathrm{CO}_{3}$ air-abrasion & $42(14 ; 73)$ & $0(0 ; 27)$ & $58(26 ; 85)$ \\
\hline & $\mathrm{SiO}_{2}$ coating & $17(1 ; 49)$ & $0(0 ; 27)$ & $83(50 ; 98)$ \\
\hline \multirow{4}{*}{$\begin{array}{l}\text { LAVA } \\
\text { Ultimate }\end{array}$} & none & $100(72 ; 100)$ & $0(0 ; 27)$ & $0(0 ; 27)$ \\
\hline & roughening & $67(33 ; 91)$ & $0(0 ; 27)$ & $33(8 ; 66)$ \\
\hline & $\mathrm{Al}_{2} \mathrm{CO}_{3}$ air-abrasion & $67(33 ; 91)$ & $0(0 ; 27)$ & $33(8 ; 66)$ \\
\hline & $\mathrm{SiO}_{2}$ coating & $67(33 ; 91)$ & $0(0 ; 27)$ & $33(8 ; 66)$ \\
\hline \multirow{4}{*}{$\begin{array}{l}\text { Filtek } \\
\text { Supreme } \\
\text { XTE } \\
\text { (control) }\end{array}$} & none & $100(72 ; 100)$ & $0(0 ; 27)$ & $0(0 ; 27)$ \\
\hline & roughening & $25(4 ; 58)$ & $50(20 ; 79)$ & $25(4 ; 58)$ \\
\hline & $\mathrm{Al}_{2} \mathrm{CO}_{3}$ air-abrasion & $0(0 ; 27)$ & $25(4 ; 58)$ & $75(41 ; 95)$ \\
\hline & $\mathrm{SiO}_{2}$ coating & $8(0 ; 39)$ & $67(33 ; 91)$ & $25(4 ; 58)$ \\
\hline
\end{tabular}

Cohesive failures occurred solely in the substrate and not in the repair composite. 